\title{
Risk Factors of Rotavirus Outbreak Among Children in Kurmuk District, Benishangul Gumuz Regional State, Ethiopia
}

\author{
Malede Mequanent Sisay ${ }^{1 *}$, Segni Mekonen Gedefa ${ }^{2}$, Addisu Jember Zeleke ${ }^{1}$ and Getachew Abebe Solleny ${ }^{3}$ \\ 1Department of Epidemiology and Biostatics, Institute of Public Health, College of Medicine and Health Sciences, University of Gondar, Ethiopia \\ 2Resident Field Epidemiology, Kurmuk Woreda Health Office \& Benishangul Regional State Health Bureau, Ethiopia \\ 3Public Health Emergency Management Officer, Benishangul Regional State Health Bureau, Ethiopia
}

Submission: August 07, 2017; Published: August 20, 2018

*Corresponding author: Malede Mequanent Sisay, Department of Epidemiology and Biostatics, Institute of Public Health, College of Medicine and Health Sciences, University of Gondar, Ethiopia, Email: maledecsa@gmail.com

\section{Abstract}

Background: Rotavirus infection (RV) is the leading cause of diarrhea in under 5 years' children. About 600,000 deaths occurred worldwide due to RV infection and $90 \%$ of deaths occurred in low-income countries. In Ethiopia, death due to RV infection is one of the top ten leading cause. The aim this study was to identify the risk factors of confirmed Rotavirus outbreak in Kurmuk district, Ethiopia.

Methods: A community based unmatched case-control study was implemented to investigate RV outbreak from February 11 to March 20, 2017. We selected 57 cases and 114 controls randomly. Data were collected using pretested structured questionnaires included sociodemographic and clinical information. Stool samples were obtained from recruited children and tested for rotavirus antigen and water samples checked. Frequencies and graphs were used to explore the data. Binary logistic regression was used to identify the risk factors. Adjusted odds ratio (AOR) with $95 \%$ confidence interval and $p$-value $<0.05$ were considered statistically significant association. Model goodness of fit test was assessed using the Hosmer-Lemeshow.

Results: Out of the total 585, 303 (51.8\%) were male children with mean age 23 months (SD=10.3). The overall attack rate was 25 cases per 1000. Fourteen (2.4\%) deaths were observed. The risk factors were contact with cases (AOR 4.46; 95\% CI 1.331-18.53), unavailability of latrine (AOR 12.98; 95\% CI, 2.66-62.41), improper handling of drink water (AOR 13.88; 95\% CI,5.06-38.05), not washing hands after cleaning child stool (AOR 4.524; 95\%CI 1.303-15.705), not washing hand after defecation (AOR 7.22; 95\% CI,1.4-37.25) and being vaccinated (AOR 10.19; 95\% CI,166- 62.41). In contrast, washing hand using soap/ash reduce infection of rotavirus (AOR 0.209; 95\% CI, 0.065-0.991).

Conclusion: Group A Rotavirus outbreak were identified in Kurmuk district. The risk factors were unavailability of latrine, improper handling of drink water, and not washing hands after defecation and cleaning child stool and contact with cases. Washing hands using soap/ash can reduce the risk of RV infection. Strengthen hygiene and sanitation activity reduce the infection. The further investigation on vaccine efficacy and genotype of the virus was crucial.

Keywords: Children; Risk Factors; Rotavirus Outbreak

\section{Background}

Rotavirus cause a significant proportion of childhood diarrhea worldwide leading to dehydration, hospitalization and deaths yearly [1-12]. The infection had a variation in regions and seasonal [13]. It is estimated that 111 million home care, 25 million clinic visits, 2 million hospitalizations and 600,000 deaths occurred in the worldwide in every year [14]. The case-fatality rate is higher in the developing countries due to malnutrition and barriers to accessing health services in a timely manner. It accounts more than $90 \%$ of rotavirus deaths. Study conducted in Africa reported that 49 to $65 \%$ death caused by rotavirus in 2013, including Ethiopia [15]. In contrast, in the United States of America only 20-60 deaths happened per year [16].
In low income country, the reported showed the prevalence of rotavirus inflated in African countries [12,16-18] . However, the annual rate is decline from $42.5 \%$ in 2000 to $37.3 \%$ in 2013 due to vaccine, oral rehydration salt (ORS) and Zink supplementation $[15,19]$.

According to world health organization (WHO) report, Ethiopia was ranked in top ten countries with high under five children mortality and morbidity by rotavirus with Prevalence ranged from $15 \%$ to $44 \%$ [20-23]. Other sentinel surveillance of $\mathrm{RV}$ done at Addis Ababa indicated that the rate is decreased due to expanding of immunization $[21,23,24]$. 
However, On February 17, 2017 RV outbreak occurred at Kurmuk district, Benishangul Gumuz Regional state among under five years children.

Thus, the aim of this study was to confirm suspected rotavirus outbreak, describe epidemiology and identify risk factors of rotavirus disease in Kurmuk district, Benishangul Gumuz Regional state, Ethiopia.

\section{Methods}

\section{Study area and design}

The study was conducted in the Kurmuk district, Benishangul Gumuz Regional state, Ethiopia. Kurmuk district shares boundaries with the Khomosha district on the South, Assosa district in the West, North Sudan in North, and Sherkole district in the East.

According to 2007 national statistics, the district is divided in to 15 rural Kebeles and one town with a 22740 -total population [25]. This district is lowland area with the annual average rain fall ranges from $700 \mathrm{ml}-1000 \mathrm{ml}$ and temperature $(26 \mathrm{oc}, 35 \mathrm{oc}$ ) as well as more than $85 \%$ of area is arid desert. Currently the district has 10 health posts and one health center with dedicated staff such as health extension workers, health development forces and health professionals.

The outbreak was investigated from Feb 11, 2017 to Mar 20,2017 . Consequently, we used community-based case-control study to identify risk factors of RV case.

\section{Sample size and sampling technique}

The required Sample size was calculated using Epi Info 7.1.4 software. Controls (21\%), 2.83 Odd ratio and $43.1 \%$ exposure of cases was taken from previous studies conducted in Jimma zone [26]. Additionally, we used the following assumptions: a 95\% confidence level, $80 \%$ Power, 1:2 cases to controls ratio. Finally, we found 171 (57cases and 114 controls) samples and included randomly.

\section{Study case definition, recruitment and laboratory methods}

The district health office was collected data daily base during outbreak period using standard line list format. The team searched active cases home to home and gave information to the community on meeting, markets, churches and other public gathering places. We collected stool samples from patients and send to Ethiopian Public health Institute (EPHI) polio and measles laboratory. Samples were placed in 2-8oC till and transported in triple package to the laboratory. The maximum time samples places in refrigerator were 48 hours. Main water source of woreda collected and checked for bacteriological indicator test. We collected samples by trained professional though sterile method. Immediately after collection we transported the water samples to Regional laboratory in 2-8oC within triple package.
The standard case definitions were as follows.

a) Suspected case: Any child under five years of age with sudden onset of diarrhea with vomiting, two or more episodes within 24 hours, from Feb 11, 2017 to March 20, 2017 and residence of Kurmuk Woreda.

b) Confirmed case: Suspect case for which there is a timely stool sample and the lab results are positive for rotavirus. Outbreak is confirmed when an epidemiological link is established with a laboratory-confirmed case.

c) Controls: Any child under five years of age without diarrhea and vomiting and resident of Kurmuk Woreda within period of Feb 11, 2017 to March 20, 2017.

For analytical study, we interviewed parents of the children by using standard pretested questioner at home and at Health facilities for controls and cases respectively. At enrollment, demographic, clinical, epidemiological, environmental information and stool samples were collected. The Dependent variable was Infection of rotavirus and Independent Variables were: Age, Sex, Immunization history, Water source, Using and presence of toilet, Exclusive breast-feeding frequency and Availability of washing facility

\section{Statistical analysis}

Data were entered in Epi Info 7.1.4 and analyzed using SPSS (V20.0). Data was described by place, person (age, sex, other socio-demographic information) and time (date of onset). Binary Logistic regression models were used to assess the associations between the dependent variable (RV status) and the independent variables. Factors with a $\mathrm{p}$-value of 0.2 in the bivariate analysis and factors of biological plausibility were included in the multi-variable analysis. Adjusted odds ratio (AOR) with 95\% confidence inter al and $\mathrm{p}$-value $<0.05$ were considered statistically significant association. The fit of the model was assessed using the Hosmer-Lemeshow good ness of fit test and $\mathrm{p}$-value $>0.05$ was taken as a cutoff point.

\section{Results}

\section{Cases and incidence rates}

Figure 1 showed variation in daily numbers of measles infection from Feb 11, 2017 to March 20, 2017. A total of 585 cases were reported in infants less than 5 year of age in the districts. Two of them were confirmed rotavirus by laboratory, whereas the remain were linked epidemiologically. The index case was occurred at Dull-shetallo health post at 11/2/2017.

More than half cases $303(51.8 \%$ ) were male children with mean age of 23 months ( $S D=10.3$ months). The investigation showed that infants were more $267(45.6 \%)$ infected age group, and an additional epidemic peak was found in 23/6/2009 (49/585). The attack rate was 25 cases per 1000 under five year's population. Moreover, 14(2.39\%) deaths were recorded during the outbreak. 


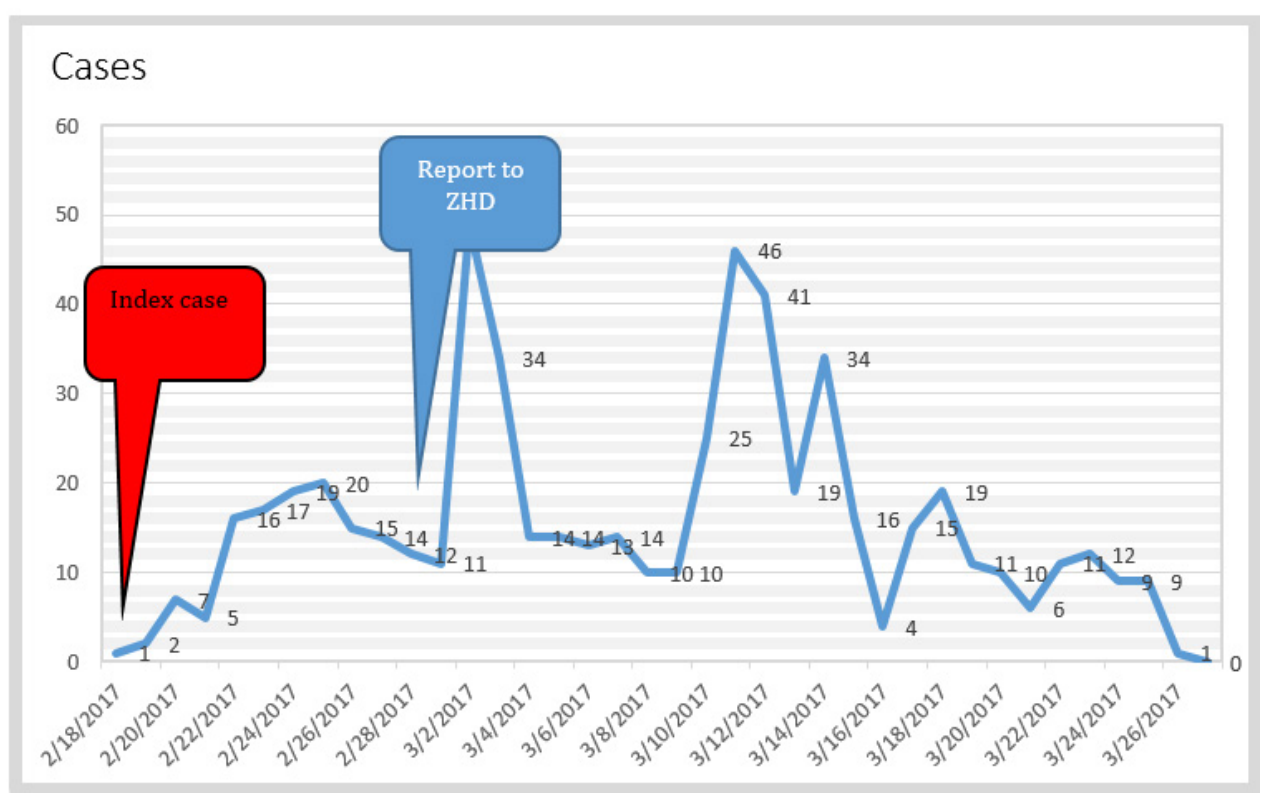

Figure 1: The date of onset of rotavirus outbreak in Kurmuk district, Ethiopia.

The study revealed that all children had diarrhea, vomit, fever and some dehydration. Before confirmation of etiologic agent patients were treated with antibiotics (cotrimoxazole) and supplements (ORS and Zink). Then after confirmation, patients were treated only with ORS and Zink. The most affected Kebeles was Dull shetallo, which accounts $156(26.6 \%)$ cases followed by Belehu Jibila 75 (12.6\%) and Horazeab 69 (11.6\%) respectively.

\section{Demographic characteristics of the studied group}

A total of 57 cases and 114 controls were selected to identify risk factors for outbreak in affected Kebeles of the Kurmuk district. The mean age was 18.9 months (SD=10.3). From cases 99.2\% had diarrhea and fever. The distribution of demographic characteristics of the study participants and risk factors for measles outbreak were described in Table 1.

Table 1: Demographic characteristics of participant in Kurmuk district, Benishangul Gumuz Region, Ethiopia.

\begin{tabular}{|c|c|c|c|}
\hline Variables & Category & Case $(\%)$ & Control (\%) \\
\hline \multirow[t]{2}{*}{ Sex of child } & M & $34(59.6)$ & $26(22.8)$ \\
\hline & $\mathrm{F}$ & $23(40.4)$ & $88(77.2)$ \\
\hline \multirow[t]{4}{*}{ Age group (in month) } & 12-Mar & $24(42.1)$ & $37(32.5)$ \\
\hline & $13-24$ & $27(47.4)$ & $43(37.7)$ \\
\hline & $25-36$ & $4(7)$ & $29(25.4)$ \\
\hline & $36-60$ & $2(3.5)$ & $5(4.4)$ \\
\hline \multirow{4}{*}{$\begin{array}{c}\text { Educational status guardian/care } \\
\text { giver }\end{array}$} & Illiterate & $31(54.4)$ & $75(65.8)$ \\
\hline & Elementary (1-8) & $18(31.6)$ & $21(18.5)$ \\
\hline & Secondary (9-12) & $5(8.8)$ & $12(10.5)$ \\
\hline & Tertiary(college+) & $3(5.2)$ & $6(5.3)$ \\
\hline \multirow[t]{5}{*}{ Occupation of guardian } & House wife & $27(47)$ & $53(46.5)$ \\
\hline & Merchants & $1(1.7)$ & $3(2.6)$ \\
\hline & Farmer & $37(64.9)$ & $87(76.4)$ \\
\hline & Students & $9(15.7)$ & $7(6.1)$ \\
\hline & cooker & $5(8.8)$ & $7(6.1)$ \\
\hline \multirow[t]{2}{*}{ Residence } & Rural & $55(96.5)$ & $110(96.5)$ \\
\hline & Urban & $2(3.5)$ & $4(3.5)$ \\
\hline
\end{tabular}


Table 2: Multivariable Logistic regression analysis of Rota virus in Kurmuk district, Benishangul Gumuz Region, Ethiopia.

\begin{tabular}{|c|c|c|c|c|}
\hline Variables & P value & COR & \multicolumn{2}{|c|}{ AOR 95\% Confidence Interval for OR } \\
\hline \multirow{2}{*}{ Being Vaccinated } & Yes & 0.012 & 10.19 & $10.19(1.66-62.41)$ \\
\hline & No & & 1 & - \\
\hline \multirow{2}{*}{ Contact with Case } & Yes & 0.017 & 4.46 & $1.331-18.53$ \\
\hline & No & & 1 & \\
\hline \multirow{2}{*}{ Exclusive Breast-Feeding Frequency ( $<$ 8perday) } & Yes & 0.0001 & 84.4 & $9.11-782.11$ \\
\hline & No & & & \\
\hline \multirow{2}{*}{ No have and use Toilet } & Yes & 0.001 & 12.908 & $2.66-62.41$ \\
\hline & No & & & \\
\hline \multirow{2}{*}{ Washing Hand using Soap/ash } & Yes & 0.046 & 0.209 & $0.065-0.991$ \\
\hline & No & & & \\
\hline \multirow{2}{*}{ Un washing after Cleaning Child Stool } & Yes & 0.017 & 4.524 & $1.303-15.705$ \\
\hline & no & & & \\
\hline \multirow{2}{*}{ Un-proper Handling of Drink Water } & Yes & & 13.88 & \\
\hline & no & 0.001 & & $5.06-38.05$ \\
\hline \multirow{2}{*}{ Un-washing after Defecation } & yes & 0.018 & 7.22 & $1.40-37.25$ \\
\hline & no & & 1 & \\
\hline
\end{tabular}

On multivariable logistic regression, having contact with cases, unavailability of latrine, improper handling of drink water, unwashing after cleaning child stool, defecation, and exclusive breast-feeding frequency less than 8 per day were risk factors for rotavirus infection. In contrast, washing hand using soap/ash reduce infection of rotavirus (Table 2).

\section{Discussion}

We identified group A Rotavirus outbreak in Kurmuk woreda, Asossa zone from $11 / 2 / 2017$ to $20 / 3 / 2017$. In addition to this Benishangul Gumuz Regional State Health Bureau declared that there was outbreak of RV in Kurmuk woreda at the same period. GAVI Surveillance report of Ethiopia showed that RV cases rose up in cooler season from October through March [24]. This outbreak began in same period with outbreak occurred in Tirana, Albania in 2000 [27]. The prevalence of rotavirus infection peaked in Ghana during the cool, dry months of January and February. In Zimbabwe a seasonal peak in the prevalence of rotavirus diarrhea occurred during the winter months [6] which is the same to cases in Kurmuk woreda. However, a less distinct seasonal peak was observed in some low-income countries (e.g., Indonesia, Vietnam, Cambodia) [13] and in equator areas (e.g., Uganda) seen year-round [6]. Some studies have noted secondary seasonal peaks in rotavirus incidence associated with periods of high rainfall and flooding [28] which contradict the season of Kurmuk woreda outbreak.

Rotavirus vaccination is the primary strategy for preventing severe rotavirus disease. Incidence and hospitalization due to rotavirus successively reduced by introduction the vaccine [29]. In United States of America, incidence of hospital visits and admission due to rotavirus gastroenteritis reduced by $86 \%$ and $96 \%$ respectively [7]. After rotavirus vaccine introduction in Rwanda, hospital admissions for diarrhea in children younger than 5 years reduced by $29 \%$ and $17 \%$ in 2013 and 2014 respectively. In the same period the number of hospital admissions for diarrhea in children younger than 1 year decreased by $55 \%$ and by $51 \%$ [21]. In contrast, vaccine efficacy such as severe gastroenteritis and length of follow-up had difference between high income and low-income nations. Rotavirus vaccines are less effective in lower income settings combination of poor immunological response caused by malnutrition, other intestinal infections, and immunosuppressant efficacy against other oral vaccine (OPV). The average efficacy for high, upper middle, lower middle, and low-income countries are $90 \%, 85 \%$, $66 \%$, and $55 \%$, respectively $[21,30]$ which is similar to in a cases of Kurmuk woreda.

Disease of rotavirus attacks children aged below 2 years and more than $75 \%$ under 12-month infants and 95\% more under the age of 18 months more affected [11]. On surveillance of rotavirus in Turkey, most rotavirus infections were recorded in children aged 12 to 23 months, and a second peak was observed in the 6 to 11 -month age group; more than $70 \%$ of rotavirus infections occurred in children less than 2 years of age [2], which is similar to our finding. However, some outbreaks of RV infection in adults have been reported [18] and even in elderly persons [31]. On large waterborne outbreak in two districts of Turkey due to rotavirus with attack rate $1 / 46$ and $1 / 66$, the mean age of the outbreak patients was 25years [10] which is slightly similar to Kurmuk woreda.

Contaminated water may be an important source of transmission in settings with poor sanitation. The waterborne transmission route may dominate during times of increased rainfall [13]. A large infantile gastroenteritis outbreak in Albania caused by multiple emerging rotavirus genotypes, common source was contaminated water [27]. On this outbreak also, the 
major identified risk factor was spring water which contradict our findings.

On this outbreak children had contact with case were more exposed to RV infection. Outbreaks of RV gastroenteritis in day-care centers and hospitals can spread rapidly among no immune children, presumably through person-to-person contacts, airborne droplets, or contact with contaminated toys [23] which similar to our finding. Nosocomial infection study on $\mathrm{RV}$ in Greece, 58\% of RV gastroenteritis in neonates was hospital acquired [17].

The limitation of this study Genotyping of rotavirus not performed in Ethiopia. Therefore, genotype of this group A rotavirus was not identified. The samples were not tested for other enteric virus like Adenovirus and norovirus which can cause gastroenteritis. Environmental sample (water) did not collected from all major water sources of sources there for the result water sample may not represent all drinking water sources in the woreda. Currently the infection was reduced by vaccinating child at age of 6 and 10 in worldwide, but my finding contradicts this idea which is risk factor for the infection. Hence it is good to identify the reason why so using cohort study and need extra investigation on vaccine efficacy.

\section{Conclusion}

We confirmed group A rotavirus outbreak among under five year's children in Kurmuk woreda, Asossa zone, Benishangul Gumuz regional state from February 11 to March 20, 2017. Risk factors of this outbreak were unwashing hands after cleaning child stool, after defecation being vaccination of Rota vaccine, exclusive breast-feeding frequency less than 8 and contact with cases. Washing hand using soap/ash can reduce the risk of RV infection. Establishment of RV surveillance site in this area and genotyping of $\mathrm{RV}$ is essential further prevention activities.

\section{Declarations}

\section{Ethics approval and consent to participate}

The woreda health office has accepted for the investigation of rotavirus (RV) outbreak through the formal letter of RHB. All parents of children were well informed about the objectives of study and we got oral consent from them.

\section{Availability of data and material}

All data supporting our findings will be shared on request.

\section{Funding}

The financial backing of this research was provided by the University of Gondar as a grant to its staff. There is no any role in the publication process.

\section{Authors' Contributions}

SM designed the study, carried out the data collection, laboratory work, participated in the statistical analysis and drafted the manuscript. MM, AJ and GA coordinated and helped to draft the manuscript. SM carried out the data collection, laboratory work, participated in the statistical analysis and drafted the manuscript. All authors read and approved the final manuscript

\section{Acknowledgements}

a) We thank the patients and their caretakers who allowed them to participate in this study. We thank the research assistants and data collectors who worked on this study.

b) We would like to thank in a special way to Ethiopian Public Health Institute Laboratory, Addis Ababa, Ethiopia and College of Medical and Health Sciences. Benishangul Gumuz Region Health Bureau/PHEM, Kurmuk woreda Health office and health facility PHEM for their unfailing, appreciated help.

\section{References}

1. Bishop R (2009) Discovery of rota virus. implication of child health. J Gastroenterol Hepatol 24 Suppl 3: S81-S85.

2. Durmaz R, Kalaycioglu AT, Acar S, Bakkaloglu Z, Karagoz A, et al. (2014) Prevalence of Rotavirus Genotypes in Children Younger than 5 Years of Age before the Introduction of a Universal Rotavirus Vaccination Program: Report of Rotavirus Surveillance in Turkey. PLoS One 9(12): e113674.

3. WHO (2009) Manual of rotavirus detection and characterization methods Manual of rotavirus detection and characterization methods Immunization, Vaccines and Biologicals. p. 1.

4. Mukherjee A, Chawla-Sarkar M (2011) Rotavirus Infection: A Perspective on Epidemiology, Genomic Diversity and Vaccine Strategies. Indian J Virol 22(1): 11-23.

5. Page AL, Jusot V, Mamaty AA, Adamou L, Kaplon J, et al. (2014) Rotavirus Surveillance in Urban and Rural Areas of Niger. Emerg Infect Dis 20(4): 573-580.

6. Mwenda JM, Ntoto KM, Abebe A, Enweronu-Laryea C, Amina I, et al. (2010) Burden and Epidemiology of Rotavirus Diarrhea in Selected African Countries: Preliminary Results from the African Rotavirus Surveillance Network. J Infect Dis 202 Suppl: S5-S11.

7. Parashar UD, Alexander JP, Glass RI, Advisory Committee on Immunization Practices (ACIP), Centers for Disease Control and Prevention (CDC) (2006) Prevention of Rotavirus Gastroenteritis Among Infants and Children. Recommendations of the Advisory Committee on Immunization Practices (ACIP). MMWR Recomm Rep 55(RR-12): 1-13.

8. Bosch A (1998) Human enteric viruses in the water environment: a minireview. Intern Microbiol 1(3): 191-196.

9. CDC/NCIRD (2012) Epidemiology and Prevention of VaccinePreventable Diseases. 12th Edition, p. 263.

10. Koroglu M, Yakupogullari Y, Otlu B, Ozturk S, Ozden M, et al. (2011) A waterborne outbreak of epidemic diarrhea due to group A rotavirus in Malatya. New Microbiol 34(1): 17-24.

11. Steele AD, Glass R (2011) Rotavirus in South Africa: From discovery to vaccine introduction. South Afr J Epidemiol Infect 1(26): 184-190.

12. Pan American Health organization (2010) Epidemiologic Surveillance of Diarrheal Diseases due to Rotavirus. Field guide 620: 1-44.

13. Patel MM, Pitzer VE, Alonso WJ, Vera D, Lopman B, et al. (2013) Global Seasonality of Rotavirus Disease. Pediatr Infect Dis J 32 (4): e134-e147.

14. Sadeghian A, Hamedi A, Sadeghian M, Sadeghian H (2009) Incidence of 
Rotavirus Diarrhea in Children Under 6 years Referred to the Pediatric Emergency and Clinic of Ghaem Hospital, Mashhad, Iran. Acta Med Iran 48(4): 263-265

15. Tate JE, Burton AH, Boschi-Pinto C, Parashar UD, World Health Organization-Coordinated Global Rotavirus Surveillance Network (2016) Global, Regional, and National Estimates of Rotavirus Mortality in Children < 5 Years of Age, 2000-2013. Clin Infect Dis: 62 Suppl 2: S96-S105

16. Bernstein DI (2009) Rotavirus Overview. Pediatr Infect Dis J 28(3): S50-S53.

17. Koukou D, Chatzichristou P, Trimis G, Siahanidou T, Skiathitou AV, et al (2015) Rotavirus Gastroenteritis in a Neonatal Unit of a Greek Tertiary Hospital. Clinical Characteristics and Genotypes. PLoS One 10(7): e0133891.

18. Mizukoshi F, Kuroda M, Tsukagoshi H, Sekizuka T, Funatogawa K, et al (2014) A food-borne outbreak of gastroenteritis due to genotype G1P [8] rotavirus among adolescents in Japan. Microbiol Immunol 58(9) 536-539.

19. WHO (2009) Weekly epidemiological record Relevé épidémiologique hebdomadaire. WHO 84: 533-540.

20. Ramos JM, Alegria I, Tessema D, Mohamed N, Tissiano G, et al. (2015) Epidemiology of Rotavirus Diarrhea among Children aged less than 5 years in rural southern Ethiopia. South east Asian J trop Med public Health 46(3): 434-443.

21. Ngabo F, Tata JE, Gatera M, Rugambwa C, Donnen P, Lepage P, et al (2008) Effect of pentavalent rotavirus vaccine introduction on hospital admissions for diarrhoea and rotavirus in children in Rwanda : a timeseries analysis. Lancet Global Health 4(2): E129-E136.

22. WHO (2013) Immunization, Vaccines and Biologicals: Estimated rotavirus deaths for children under 5 years of age. p. 1
23. Vidhya P, AP, Gunasekeran P, Arunagiri K, Sambasivam M, et al. (2015) Rota virus infections: prevalence, diagnosis and prevention. J Pediatr Sci 2(e244): 1.

24. Federal Ministry of Health Addis Ababa (2015) Ethiopia National Expanded Programme on immunization comprehensive multi-Year Plan 2016-2020.

25. EDHS, Central Statistical Agency (CSA) [Ethiopia], ICF (2016) Ethiopia Demographic and Health Survey 2016. CSA and ICF Addis Ababa, Ethiopia, and Rockville, Maryland, USA.

26. Bizuneh T, Mariam ZS, Abebe A, Lema E (2004) Rotavirus infection in under-five children in Jimma Hospital, Southwest Ethiopia. Ethiop J Health Dev 18(1): 19-24.

27. Villena C, Gabrieli R, Pintó RM, Guix S, Donia D, et al. (2003) A large infantile gastroenteritis outbreak in Albania caused by multiple emerging rotavirus genotypes. Epidemiol Infect 131(3): 1105-1110.

28. Jones FK, Ko AI, Becha C, Joshua C, Musto J, et al. (2016) Increased Rotavirus Prevalence in Diarrheal Outbreak Precipitated by Localized Flooding, Solomon Islands, 2014. Emerg Infect Dis 22(5): 875-879.

29. Bar-Zeev N, Jere KC, Bennett A, Pollock L, Tate JE, et al. (2016) Population Impact and Effectiveness of Monovalent Rotavirus Vaccination in Urban Malawian Children 3 Years After Vaccine Introduction: Ecological and Case-Control Analyses. Clin Infect Dis 62 Suppl 2: S213-S219.

30. Verguet S, Murphy S, Anderson B, Johansson KA, Glass R, et al. (2013) Public finance of rotavirus vaccination in India and Ethiopia: An extended cost-effectiveness analysis. Vaccine 31(42): 4902-4910.

31. Trop Skaza A, Beskovnik L, Zohar Cretnik T (2011) Outbreak of rotavirus gastroenteritis in a nursing home, Slovenia, December 2010. Euro Surveill 16(14): 19837.

\section{Your next submission with Juniper Publishers} will reach you the below assets

- Quality Editorial service

- Swift Peer Review

- Reprints availability

- E-prints Service

- Manuscript Podcast for convenient understanding

- Global attainment for your research

- Manuscript accessibility in different formats

(Pdf, E-pub, Full Text, Audio)

- Unceasing customer service

Track the below URL for one-step submission https://juniperpublishers.com/online-submission.php 